\title{
Prospects of solar power generation in dry regions: the case of Arar in KSA
}

\author{
S. Sawallha ${ }^{1}$, J. Jaber ${ }^{2}$ and T. Abu Mansour ${ }^{1}$ \\ ${ }^{1}$ Faculty of Engineering \\ Northren Bordar University \\ Arar (Kingdom of Saudi Arabia) \\ Phone; +966595131897,fax number:+ 96646640705, e-mail:sawalhasalameh80@ yahoo.coc, \\ abumansourt@windowslive.com , \\ ${ }^{2}$ Faculty of Engineering Technology, Al-Balqa' Applied University, Amman, Jordan \\ P.O. Box: 15008 Amman \\ Phone +962 6 4790333, fax +962 6 4790350, e-mail: jojaber@ gmail.com
}

\begin{abstract}
The prim aim of this paper is to propose and analyze technical and economic dimensions concerning the integration of solar power (PV) unit(s), in the existing typical conventional power generation system, in the absence of a feed-in tariff scheme. The basic scenario examined in this work assessed possible electricity unit cost taking into account the penetration of PV modules of about 5 to $10 \mathrm{~kW}$ PV systems as roof-tops for residential use, without storage capability in prevailing local conditions in the northern region of KSA, i.e. city of Arar. Based on the input data and assumptions made, the simulations indicated that the scenario to meet the electrical demand of Arar would require installing at least 20-30 central modules, with a capacity of about $10 \mathrm{MW}$ each. But it is not possible to meet the total electrical demand by employing distributed PV modules. In addition, the cost The estimated cost of produced electricity is about 0.1-0.12 US\$/kWh and considered very high compared with the current prices of about US\$ 0.013 per $\mathrm{kWh}$. Without government incentives, i.e. feed-in-tariff or any other financial scheme aiming to encourage the utilization of renewable energy resources, such systems will not be feasible or find its way in KSA. However, the sensitivity analysis on current fuel prices, used for power generation, showed that increasing the local fuel prices would make such plants more economically attractive compared with conventional systems.
\end{abstract}

\section{Key words}

$\mathrm{PV}$, renewable energy, electricity generation, KSA

\section{Introduction}

Kingdom of Saudi Arabia (KSA) is a large country, with an area of 2.3 million $\mathrm{km}^{2}$, and considered one of the richest countries in terms of indigenous energy sources; both conventional, e.g. oil and gas, and renewable, e.g. solar and wind energy. On the other hand, KSA is a developing country with relatively high growth rates of electrical consumption, of about $5 \%$ per annum [1]. It is expected that during the next two decades, more than US $\$ 100$ billion will be invested to develop its power sub-sector. The national power grid system supply electricity to approximately $80 \%$ of the population living in cities, towns and industrial centres. But there are small communities in remote areas that rely on diesel units as an independent source of electrical energy since extending the national electrical grid is considered uneconomical [2]. It is really cumbersome to maintain regular supply of fuel and to ensure the continuous electricity supply during breakdowns and scheduled shutdowns of the diesel units. Such communities or villages represent a significant potential for renewable energy applications. The importance of using renewable energy in KSA will not only be confined to meeting the electrical demand of remote sites, but can also contribute to the national grid, thereby helping to meet the growing peak-load demand which usually occurred during the summer season.

In Saudi Arabia, the per capita energy consumption has reached to $21 \mathrm{kWh} /$ day in 2011 compared to 20 and $19.4 \mathrm{kWh} /$ day in 2008 and 2007, respectively [3]. On an average during the last 25 years, around $4.1 \%$ annual increase in per capita energy per day has been observed which is really significant and needs to be addressed immediately. Moreover, the total installed capacity in KSA, as of $1^{\text {st }} \mathrm{Jan}$. 2012, was 51,000 MW compared to $32,000 \mathrm{MW}$ in 2004 , due to the continuous increase in the peak-load. The annual energy production, in 2011, exceeded $190,000 \mathrm{GWh}$ with an average heat rate of about 10,907 $\mathrm{BTU} / \mathrm{kWh}$ and the total fuel consumption reached 51 million toe [4]. Based on the assumption that the local price of oil is 60 US\$/barrel, then the total cost of consumed fuel for power generation on that year would be $2.142 \times 10^{10}$ US\$. Thus, even a small improvement in the efficiency of existing power stations and/or contributions of new renewable energy power generation projects will help in reducing the cost of generated power and save the environment.

Even though KSA is a leading oil producer, with a production rate of around 10 million barrels per day, the government is keenly interested in taking an active part in the development of new technologies for exploiting and utilizing renewable energy sources, such as solar energy. Applications of solar energy in KSA have been growing since 1960 [5]. Research activities commenced with small-scale university projects during 1969, and systematized major R\&D work for the development of solar energy technologies was started by the King Abdulaziz City for Science and Technology (KACST) in 1977. For the last two 
decades the Energy Research Institute (ERI) at KACST has conducted major research, development and demonstration work in this field. The ERI has a number of international joint programs in the field of solar energy. The solar energy R\&D activities include lighting, cooling, water heating, crop/fruit drying, water desalination, the operation of irrigation pumps, and the operation of meteorological stations, and in providing road and tunnel lighting, traffic lights, road instruction signals and for small applications at remote sites [6]. However, effective utilization of solar energy in KSA has not yet made reasonable progress mainly due to several obstacles, the most important are:

- $\quad$-Availability of cheap oil and its derivatives.

- $\quad$ The dust effect, which in some parts may reduce the incoming solar radiation by about $20 \%$, or even more in many locations.

- $\quad$-Prevailing governmental subsidies for petroleum products and electricity, i.e. low cost of conventional energy forms.

- $\quad$ There is no single program or incentives oriented to advocate the employment of various renewable energy sources for different applications.

The prime aim of this article is to investigate the feasibility of distributed PV modules for residential applications in Arar city, in KSA.

\section{Solar Energy in KSA}

KSA is blessed in an abundant high annual solar radiation rates with an average of about $2200 \mathrm{kWh} / \mathrm{m}^{2}$, which is believed by researchers as valuable and important source as crude oil for the future development of the country. Solar radiation data is available from different sources such as the Meteorology and Environment Protection Administration (MEPA) [7], Saudi Aramco and King Fahd University of Petroleum and Minerals (KFUPM). Reliable quantitative data on the daily and annual distribution pattern of solar energy at a given location is essential not only for assessing the economic feasibility of solar energy utilization, but also for the thermal design and environmental control of buildings and greenhouses. But it worth mentioning that the existing Atlas for Solar Radiation does not cover all regions in KSA, since it was based on data collected by old and un-calibrated instruments; and the magnitude of global solar radiation has changed due to global weather variations and the environmental impacts of the Gulf Wars. However, there is an ongoing project to update the Solar Atlas. In which twelve locations throughout the country were carefully selected and connected to a central unit for data collection and all employed instruments and measuring devices are calibrated on a regular basis (at 6 month periods) in order to derive reliable and accurate data.

Site and data description:

The city of 'Ar'ar was founded in 1950, after the construction of the Aramco oil pipeline (Tapline) was completed: it was initially an oil pumping station with a health center and worker housing. Ar'ar is located to the north-east of Saudi Arabia (at Latitude: $30^{\circ}$ $54^{\prime} 21 \mathrm{~N}$, Longitude: $41^{\circ} 8^{\prime} 20 \mathrm{E}$ ) close to the Iraqi border, on the international highway leading to Jordan. Its population is estimated at, according to the latest official government statistics, is 240,000 , while the total population of the northern-border province is about 900,000 inhabitants. The prevailing weather is hot in summer, with temperature touching $50{ }^{\circ} \mathrm{C}$, or even more, during day time, and cold winter with temperatures below freezing during night time, and relative humidity is very low and skies are clear most of the time. Thus, open land experiences high intensities of solar radiation and long hours of sunshine duration.Winds generally blow from the east or west but rarely from the south. It is noteworthy that the rainfall in the region has declined gradually over recent years, but snow is not uncommon, falling on average every two to three years.

It was found that the area receives, on an average, more than 5.5 $\mathrm{kW} / \mathrm{m}^{2}$ of global solar radiation each day on a horizontal surface. The overall mean value of sunshine duration, obtained by using all the values from 35 locations, was found to be 9 , i.e. 8.89 , hours each day and approximately 3245 hours each year [8].

\section{Existing Power Supply in Arar}

Electricity supply in Arar city and nearby area is based on a central power plant using open cycle gas turbines firing diesel oil. Fig. 1 summarize main performance indicators of the power plant. As can be clearly seen that the maximum power generation (red curve) occurred during summer season, i.e. May-October, and during winter months [9]. Hence fuel consumption (blue curve) is following exactly the power demand with a very high coloration factor of almost a unity.

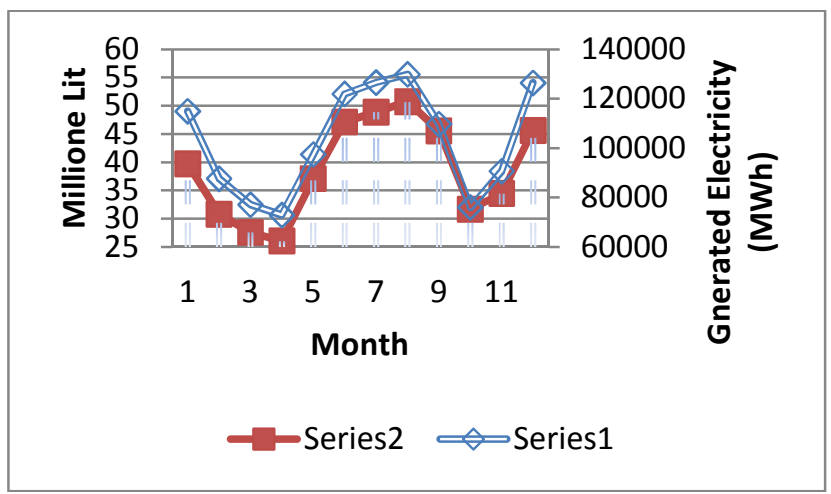

Fig. 1. Electricity generation and fuel consumption at Arar power station in 2011

Such trend in electricity demand in Arar city is attributed to the high demand during summer months due to the heavy use of air conditioning systems and ventilation fans. It is important to note that specific fuel consumption increased significantly during summer, i.e. 385 lit/MW in summer compared with 350 lit/MW in winter, as a result of higher temperatures during summer. Thus, using centralized or distributed PV systems will assist in reducing fuel consumption during summer and consequently GHG emissions.

\section{Cost of PV System}

The installed PV system cost was estimated at retail prices prevailed during 2012 at about US\$ 3.2 per one watt peak [10]. Although, there is a decline trend in the price of PV modules in the international market, the analysis conducted in the current study was based on a fixed price, based on 2012 figures. It did not allow for declining system prices in 2013 to 2020. In the open literature, it is reported that factory gate or spot prices of modules for crystalline silicon (c $-\mathrm{Si}$ ) fell to a range of US\$ $1.02-1.24$ per $\mathrm{W}$ at the end of 2012 , and expected to continue decreasing depending on the developments markets in $3^{\text {rd }}$ world countries. The price for non-Chinese mono-crystalline silicon modules was reported at US\$ 1.01 per $\mathrm{W}$ and for thin-film modules were reported at US\$ $0.84-0.93$ per $\mathrm{W}$. The final cost of PV system will also depend on the distribution cost of these modules in the market, and it is expected that the retail price is about 35 to $45 \%$ over the factory gate price [11].

The basic studied scenario uses current prices as estimated by different sources: assuming that the cost breakdown of an installed PV system in KSA is composed of the factory gate price of c-Si modules at US\$ 1.0 per W and inverter cost at US\$ 
0.56 per W. Racking and mounting systems would be manufactured and installed locally over flat rooftops at a cost of about US\$ 0.10 per W. Other electrical material and electrical labour cost was estimated at US\$ 0.10 per W. Shipping and handling was estimated at US\$ 0.06 per W. In this study, assuming unforeseen expenses and profit and overhead at $40 \%$, the current installed system cost would be around US\$2,548 per $\mathrm{kW}$.

\section{Discussion and Results}

By using conventional PV panels, as roof tops, the estimated annual average generated power ranges between 1750 to 3300 $\mathrm{kWh}$ per year, depending on the installed capacity of the employed system. If a $5 \mathrm{~kW}$ system is taken as a reference, then an average of about $1750 \mathrm{kWh} /$ year based on the average solar intensity in Arar. Yet, very few households have installed PV systems, in KSA, mostly in rural areas and as off-grid systems. The Saudi government and some of the local authorities and civil society organizations have successfully installed few small systems to generate power to small villages and for street lighting as pilot projects. However, the use of PV systems to generate electricity has been very limited in KSA with negligible impacts on the production capacity. The major obstacles inhibiting the use of PV modules historically are:

- Lack of regulatory framework and national policies to advocate development and employment of renewable energy (RE) schemes.

- The high cost of RE systems.

- The lack of government incentives and the lack of adequate financing schemes.

- The lack of technical expertise, know-how and awareness.

- Reluctance of the concerned authorities, including the electricity company and the absence of government subsidy such as feed-in-tariff (FiT).

Based on the prevailing conditions in Arar, the annual generated electricity by the $5 \mathrm{~kW}$ PV module is approximately $8,750 \mathrm{kWh}$, which is good enough and would contribute significantly in reducing the load on the gas turbine based power station. But the equivalent cost of this power is about US\$ 116 based on the local electricity tariff of US\$ 0.0133 per $\mathrm{kWh}$, which is far below than actual generation cost if the price of fuel is taken on the basis of current prices in the international spot market. It is predicted that the reasonable actual cost of electricity generation ranges US\$ 0.08-0.12 per $\mathrm{kWh}$, and this would shorten the payback period to 18 and 12 years, respectively. Based on the present electricity tariff for the residential sector in KSA, the simple payback period, i.e. 21 years, of such system would be more than the expected life time of the PV module. Maintenance cost and other costs related to licensing, insurance, connection, etc., are ignored, and when added the payback period would be longer. Further, the analysis did not account for changing the inverter once in a twenty year lifetime; also no interest charge is considered. The latter may extend the payback period by at least another 7-10 years depending on the rate of interest the charged by local banks or lending institutions in KSA. However, savings in greenhouse gases (GHG) emissions are not considered, i.e. returns from $\mathrm{CO}_{2}$ reductions were not accounted for in the analysis, and thus, allowing an additional safety factor. Fortunately, the actual payback period is expected to be shorter than expected in this article. It should be mentioned that the inclusion of storage batteries option was not considered in this research. This will serve in adding extra costs on the PV installation cost; however, it can lead to feeding the grid with electricity at peak times, and will enable consumers to use their extra energy at other times, e.g. peak consumption times.

It is recommended that concerned Saudi authorities, e.g. Arar Municipality and the Governorate, to design and run a pilot project that will enable local citizens to install PV modules in their houses. In this project, consumer who agrees to install a PV generating unit that produces an equal amount of his monthly electricity consumption will get a free PV system, i.e. at zero cost, and be charged a percentage of the cumulative charge of his category, i.e. monthly electricity bill. The government benefits come from the following: (i) receive an income that is equal to the consumer paid charges, (ii) reduce its subsidy to a large extent, which may become zero, as consumers will serve themselves in the context of electricity consumption, (iii) reduction of GHG emission levels, and (iv) be internationally awarded. Such project could be considered as win-win situation for both the consumers and the government over the assumed life time (or lifespan) of the PV generating unit. The benefits attained can be easily evaluated and economically computed in order to define the terms of the proposed project. The project could be extended to investigate the economics of introducing advanced and highly efficient street lighting, i.e. LED, together with PV modules.

To sum up the main result is obvious for all that such system will not cover its cost during its expected life time and without proper governmental incentives and subsidy schemes, such as FiT, small PVs as roof-tops for residential applications will not see the light in KSA under the existing level of electricity tariff.

\section{Conclusion}

The fact that there are abundant oil and gas resources in KSA and enough to supply the local consumption and generated the needed income to finance the national budget and economy should be changed. Renewable energy sources, such as solar and wind, can serve to fill the growing national demand, especially for power generation. The harnessing of such resources must be supported by a robust and ambitious incentive schemes which runs in parallel with an up-to-date energy efficiency program. This will surely contribute in a positive way to solve the current problems of the electricity sector in KSA. In this research the solar energy was the focus. As such, the role of the installation of PV generating units to enhance the local power system in Arar in terms of security and economy was investigated. It can be stated with confidence that PV modules will not see the light And find its way in the local market under the prevailing conditions in KSA. This could be attributed to various factors, but the most important being the heavily subsidized electricity tariff, lack of regulatory frame work and the complete absence of governmental promotion and incentives schemes. Without these, it is impossible to start the implementation of any renewable based generation, in general, and PV generation in particular. This, for sure, such programmes will lead to a win-win situation, where the government wipes out its subsidies to the electricity tariff, and the consumer will locally generate the majority or all of his own electricity needs, and have the privilege of paying a fraction of incurred bill amount.

\section{References}

[1] Anon, Yearly Statistical Report 2010, Saudi Statistical Corporation, Ryiad, KSA.

[2] Anon, Annual Report 2011, Saudi Electricity Company, Reyiad, KSA.

[3] Anon, Electricty: growth and development in the Kingdom of Saudi Arabia 2011, Ministry of Water \& Electricity, Office of the Deputy Minister, Information \$ Statistics Center, 2011, Reyiad, KSA.

[4] S. Rehman, L. Al-Hadhrami, "Study of a solar PV-diesel- 
battery hybrid power system for a remotely located population near Rafha, Saudi Arabia”, in Energy 2010, Vol. 35, pp. 4986-4995.

[5] M. Elhadidy, S. Shaahid, "Wind resources assessment of eastern coastal region of Saudi Arabia", in Desalination 2007, Vol. 209, pp. 199-208.

[6] H. Kaylani, M. Ashhab and A. Abdallah, "Experimental combined PV solar and absorption system", in Proc. of Global conference on renewable and energy efficiency for desert regions GCREEDER 2011, Amman, Jordan.

[7] Anon. Annual Report 2011, Meteorology and Environment Protection Administration, Rayiadh, KSA.

[8] S. Said, I. El-Amin and A. Al-Shehri, "Renewable energy potential in Saudi Arabia", Report 2010, King Fahd University of Petroleum \& Minerals, Dharan, KSA

[9] Anon. Annual Operation Report 2011, "Arar Power Station Operation Report-2011", Arar, KSA.

[10] N. Abu-Shikhah, A. Hiasat and W. Al-Rabadi, "A photovoltaic proposed generation promotion policy - the case of Jordan", in Energy Policy 2012, http://dx.doi.org/10.1016/j.enpol.2012.06.055.

[11] H. Lund, 2010, "Renewable energy systems: the choice and modelling", Elsevier publicaintions. 